AIAA-2000-2905

\title{
THERMAL DESIGN TO MEET STRINGENT TEMPERATURE GRADIENT/STABILITY REQUIREMENTS OF SWIFT BAT DETECTORS
}

\author{
Michael K. Choi" \\ NASA Goddard Space Flight Center \\ Greenbelt, MD 20771
}

\begin{abstract}
The Burst Alert Telescope (BAT) is an instrument on the National Aeronautics and Space Administration (NASA) SWIFT spacecraft. It is designed to detect gamma ray burst over a broad region of the sky and quickly align the telescopes on the spacecraft to the gamma ray source. The thermal requirements for the BAT detector arrays are very stringent. The maximum allowable temperature gradient of the 256 cadmium zinc telluride (CZT) detectors is $1^{\circ} \mathrm{C}$. Also, the maximum allowable rate of temperature change of the ASICs of the 256 Detector Modules (DMs) is $1{ }^{\circ} \mathrm{C}$ on any time scale. The total power dissipation of the DMs and Block Command \& Data Handling $(\mathrm{BCDH})$ is $180 \mathrm{~W}$. This paper presents a thermal design that uses constant conductance heat pipes (CCHPs) to minimize the temperature gradient of the DMs, and loop heat pipes (LHPs) to transport the waste heat to the radiator. The LHPs vary the effective thermal conductance from the DMs to the radiator to minimize heater power to meet the heater power budget, and to improve the temperature stability. The DMs are cold biased, and active heater control is used to meet the temperature gradient and stability requirements.
\end{abstract}

\section{INTRODUCTION}

The BAT is one of the three telescopes on the SWIFT spacecraft. The SWIFT mission is part of the NASA Medium-Size Explorer (MIDEX) Program, and is managed by Goddard Space Flight Center (GSFC). It is scheduled to launch in 2003. The SWIFT mission is a first of its kind of multi-wavelength transient observatory for gamma ray burst astronomy. Its mission life is 3 years. The altitude of SWIFT is 600 $\mathrm{km}$, and the inclination is $22^{\circ}$.

BAT is being developed at GSFC. There are 256 DMs in the Detector Array Plane (DAP) of the

Associate Fellow

' Copyright $(0) 2000$ The American Institute of Aeronautics and Astronautics. Inc. No copyright is asserted in the Lnited States under Title 17. U.S. Code. The U.S. Government has a royaltyfree license to exercise all rights under the copyright claimed herein for Governmental purposes. All other rights are reserved by the copyright owner.
BAT instrument. Each DM consists of an $8 \times 16$ subarray of CZT detectors, an ASIC with fanin, an ASIC controller, an $\mathrm{ADC}$ (with 4-channel mux), a biasing contact to the CZT, a transceiver to the $\mathrm{BCDH}$, and the miscellaneous support electronic. The power dissipation of each DM is estimated to be $0.5779 \mathrm{~W}$. Therefore, the total power dissipation of the $256 \mathrm{DMs}$ is $148 \mathrm{~W}$. Each DM block holds 16 DMs. The Detector Array Plate, $1.3 \mathrm{~m} \times 1 \mathrm{~m}$, holds all the 16 Blocks. It also provides the mounting surface and the positional stability for the Blocks. The DAP is enclosed by the graded- $Z$ shields on the sides and coded mask at the top. Figure 1 shows the BAT design. The BCDH PWBs are mounted to the bottom facesheet of the aluminum honeycomb of the Detector Array Plate. The power dissipation of the $\mathrm{BCDH}$ is 32 W. Aluminum inserts conduct heat from the PWBs to the top facesheet. The current total power dissipation of the DMs and BCDH is $180 \mathrm{~W}$. Figure 2 shows the CZT detector and ASIC on the DM printed wiring board (PWB).

Figure 1. BAT Configuration.

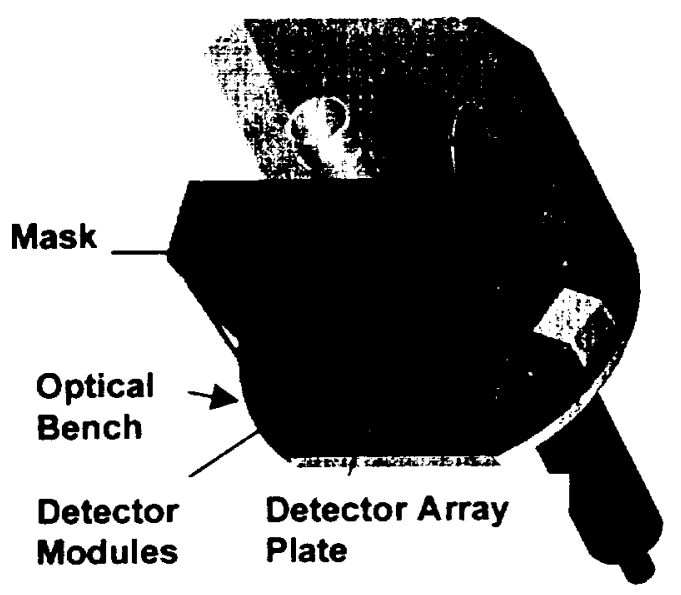

\section{THERMAL REQUIREMENTS}

The thermal requirements for the BAT detector arrays are very stringent. The maximum allowable temperature gradient of the CZT detectors of the 256 DM PWBs is $1{ }^{\circ} \mathrm{C}$. Also, the maximum allowable rate of temperature change of the ASICs of the $256 \mathrm{DM}$ PWBs is $1{ }^{\circ} \mathrm{C}$ on any time scale throughout the 3-year

1 
mission. The CZT detector works in the $0^{\circ} \mathrm{C}$ to $20^{\circ} \mathrm{C}$ range. But, a much larger radiator is needed for a $0^{\circ} \mathrm{C}$ CZT detector temperature than for a $20^{\circ} \mathrm{C} \mathrm{CZT}$ detector temperature. Presently, a $20^{\circ} \mathrm{C} \mathrm{CZT} \mathrm{detector}$ is specified.

Figure 2. BAT DM PWB.

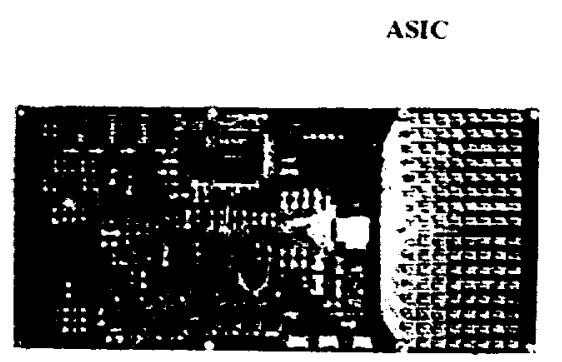

CZT Detectors

\section{Uncertainty Margin}

\section{THERMAL DESIGN}

Traditionally, a $5^{\circ} \mathrm{C}$ uncertainty margin is required for flight temperature predictions. If active heater control is used and there is sufficient heater power margin, the $5^{\circ} \mathrm{C}$ margin can be waived. For BAT, the flight temperature prediction of the CZT detectors must meet the $20^{\circ} \mathrm{C} \pm 0.5^{\circ} \mathrm{C}$ temperature requirement, and a $5^{\circ} \mathrm{C}$ margin is not applicable. If active heater control is used, the heater capacity must have sufficient margin (at least $25 \%$ ).

\section{Approach}

The thermal design concept of BAT to meet the stringent temperature gradient and stability requirements is as follows. The DMs are cold biased, and active heater control is used. Adequate thermal conductances between the PWBs and the DM Blocks are ensured. The DM PWBs have adequate copper planes to conduct heat from the ASICs to the Block structure. The mounting feet of each DM Block are bolted to the Detector Array Plate. Thermal gaskets are used to increase the interface thermal conductance between the Blocks and Detector Array Plate. The Blocks are made of an aluminum alloy. The Detector Array Plate is an aluminum honeycomb core with a $0.1016 \mathrm{~cm}(.04$ inch) aluminum facesheet on the top and bottom. Eight CCHPs are embedded in the honeycomb core of the Detector Array. They are spaced $9.14 \mathrm{~cm}$ (3.6 inch) apart. The CCHPs are made of aluminum, and have a $1.27 \mathrm{~cm}(0.5$ in) diameter. They interface with the top facesheet, and mounting feet of the DM Blocks are bolted to the heat pipe flanges. The working fluid is ammonia. The CCHPs have redundancy. They minimize the temperature gradient of the DMs. Presently, the temperature gradient from the DM PWB to the CCHPs is calculated to be $6^{\circ} \mathrm{C}$.

Kapton heaters and electronic proportional controllers control the temperatures of the CZT detectors precisely to within $\pm 0.5^{\circ} \mathrm{C}$ of the temperature requirement, and maintain the temperature stability of the ASICs. The tolerance of the controller is $\pm 0.25^{\circ} \mathrm{C}$. Temperature feedback loop is from the thermistors on the Block structure to the heater controllers. Presently, the YSI 44910 thermistor $^{1}$ is used to feed the temperature of the DM structure to the heater controller. According to YSI, the tolerance of the temperature is $\pm 0.1^{\circ} \mathrm{C}$ at $20^{\circ} \mathrm{C}$, and increases to $\pm 0.2^{\circ} \mathrm{C}$ at $-40^{\circ} \mathrm{C}$. The set point of the controllers is required to be adjustable in flight such that the detector temperature can be adjusted to achieve maximum science. Each of the 16 Blocks has two redundant heater zones. Each zone has a miniature electronic proportional controller, a thermistor, and a number of kapton heaters. The heaters and electronic controllers are bonded to the interior of the Block structures using a thermally conductive epoxy.

The DAP is radiatively isolated from the coded mask at the top and graded- $Z$ shields surrounding the BAT. Radiative isolation is achieved by adding a $0.0508 \mathrm{~mm}$ (2-mil) kapton, aluminized on both sides, to the interior of the coded mask and graded- $Z$ shields, and the exterior of the DAP. The Detector Array Plate is thermally isolated from the optical bench by five titanium flexures. The exterior of the coded mask is insulated with multi-layer insulation (MLI) blankets, which have 5 inner layers. The MLI is thin enough to meet the gamma-ray attenuation requirement. The exterior of the graded- $Z$ shields is insulated with MLI blankets, which have 18 inner layers. One possibility is to integrate the graded- $Z$ shields into the MLI.

The location and orientation of the BAT radiator are chosen so that there is no direct solar radiation incident on the radiator for all sun angles, $45^{\circ}$ to $180^{\circ}$, in the SWIFT mission. Albedo flux and Earth emitted IR radiation are the only environmental heat fluxes that affect the temperature gradient and temperature stability of the BAT detector arrays. They vary from day to night, and from summer solstice to winter solstice. Also, degradation of the thermal coating on the radiator has an impact on the temperature gradient and stability. When a coating degrades, its solar absorptance increases, and the albedo flux absorbed increases.

\section{Radiator Thermal Coating}

Albedo flux is maximum at orbit noon and it vanishes in the Earth's eclipse. Also, it is higher in the winter solstice than in the summer solstice. It is a 
major factor that causes the temperature instability of the BAT DM PWBs. One way to minimize the effect of albedo flux is to select a thermal coating that has a very low solar absorptance at the beginning of life (BOL), and a small degradation over a 3-year mission life for the radiator. AZ-Tek's AZW/LA-II white paint is likely the best candidate thermal coating for the BAT radiator, based on its absorptance and emittance. The Thermal Coatings Committee at GSFC $^{2}$ recommends the following thermo-optical properties for this coating in the SWIFT mission, when it is not exposed to direct solar radiation. The solar absorptance is 0.08 and hemispherical emittance is 0.91 at BOL. The solar absorptance is 0.12 and hemispherical emittance is 0.90 at the end of life (EOL). Its high emittance provides a high radiation coupling to space. The flight data of the AZW/LA-1I white paint shows that initially the solar absorptance was 0.088 , and after 48 days in space flight, it increased to 0.095 , and after 197 days, it increased to 0.103 . $^{3}$ They show that the degradation of this paint in space is very small. Preliminary results of an ongoing ultraviolet exposure test at GSFC show that the paint is stable. Also, the AZW/LA-1I white paint will be flying on the GSFC calorimeter on the EO-1 spacecraft, which is scheduled to launch later this year. EO- 1 is an Earth orbiting spacecraft, and has an altitude of $705 \mathrm{~km}$. More testing of this paint will be performed at GSFC.

Figure 3 shows the orbital transient combined albedo flux and Earth emitted IR radiation absorbed by the radiator in the hot case for different sun angles. The absorbed flux is highest at a $90^{\circ}$ sun angle. For this reason, the worst hot case thermal analysis is performed at a sun angle of $90^{\circ}$.

Figure 3. Combined Albedo and Earth IR Absorbed by BAT Radiator at EOL in Winter Solstice.
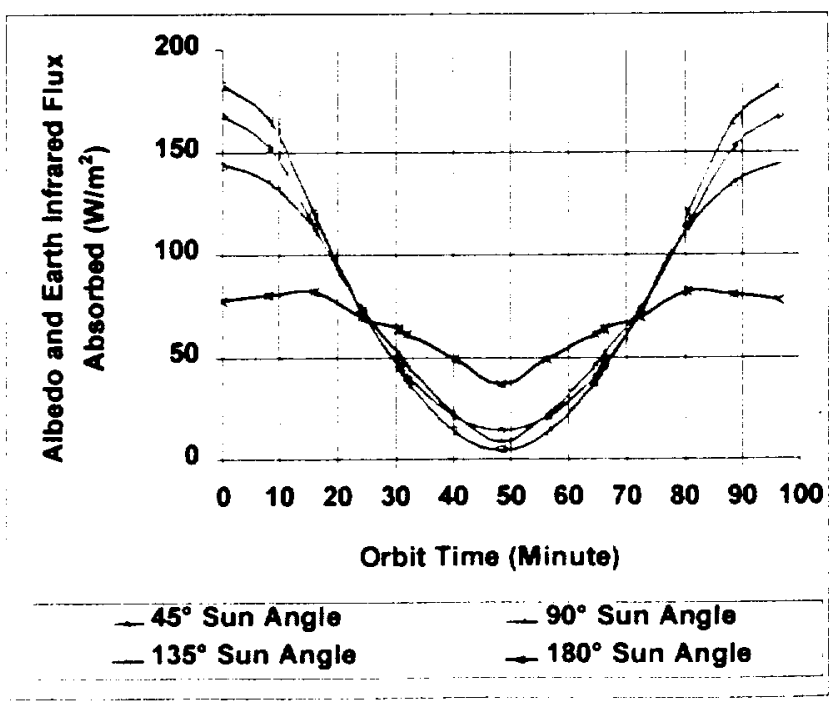

Figure 4 shows the orbital transient combined albedo flux and Earth emitted infrared (IR) radiation absorbed by the radiator in the cold case for different sun angles. The absorbed flux is lowest at a sun angle of $180^{\circ}$. For this reason, the worst cold case thermal analysis is performed at a sun angle of $180^{\circ}$.

Figure 4. Combined Albedo and Earth IR Absorbed by BAT Radiator at BOL in Summer Solstice.

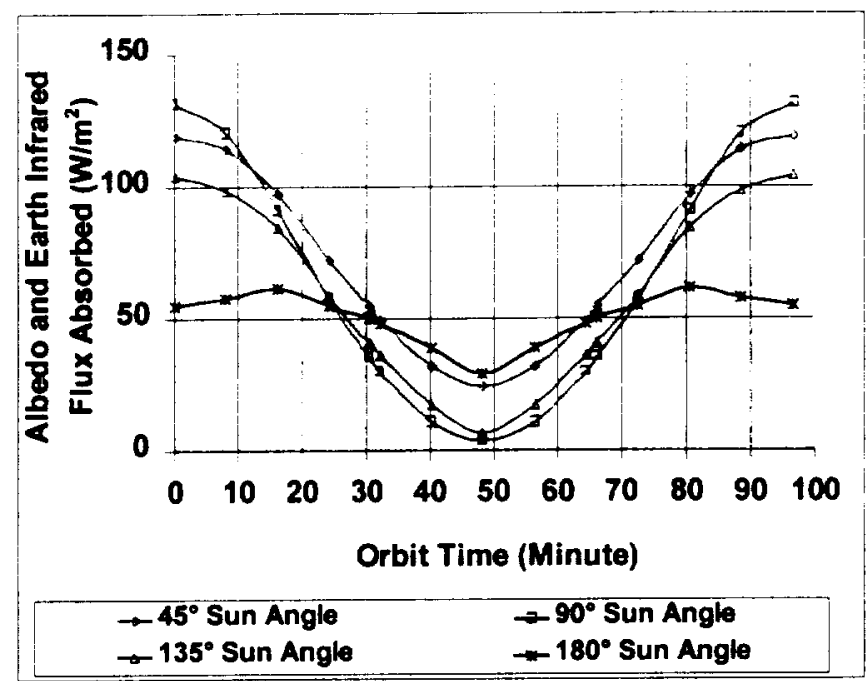

\section{THERMAL ENERGY BALANCE}

\section{Operating Mode}

For a given radiator area, the thermal energy balance of the radiator at thermal equilibrium is

$Q_{\mathrm{r}}=\mathrm{Q}_{\mathrm{DAP}}+\mathrm{Q}_{\text {Albedo }}+\mathrm{Q}_{\mathrm{EIR}}+\mathrm{Q}_{\mathrm{SC}}+\mathrm{Q}_{\mathrm{op} \text {-htr }}$

where $Q_{r}=$ heat radiation from radiator to space,

$\mathrm{Q}_{\text {DAP }}=$ power dissipation in DAP,

$Q_{\text {Albedo }}=$ Albedo flux absorbed,

$\mathrm{Q}_{\mathrm{EIR}}=$ Earth emitted $\mathrm{IR}$ radiation absorbed,

$\mathrm{Q}_{\mathrm{SC}}=$ heat radiation from spacecraft, particularly solar arrays, to radiator,

$\mathrm{Q}_{\mathrm{op} \text {-htr }}=$ heater power.

$Q_{D A P}$ is constant (currently $180 \mathrm{~W}$ ), and there is no duty cycle. But, $\mathrm{Q}_{\mathrm{Albed}}, \mathrm{Q}_{\mathrm{EIR}}$, and $\mathrm{Q}_{\mathrm{SC}}$ vary from orbit noon to Earth's eclipse, from summer solstice to winter solstice, from BOL to EOL, and from one sun angle to another. If the conduction coupling from the DAP to the radiator is constant, in order to maintain the CZT detector and ASIC temperatures constant, the radiator temperature needs to be constant, and therefore $Q_{r}$ needs to be constant. As a result, $Q_{o p-h e r}$ needs to be varied. The value of $\mathrm{Q}_{\mathrm{op} \text {-hu }}$ is largest in the eclipse at BOL, and is smallest at orbit noon at EOL.

\section{Safehold Mode}

In the safehold mode, the power dissipation of the DM PWBs and BCDH PWBs is zero. The thermal energy balance of the radiator at thermal equilibrium in the safehold mode is:

$$
Q_{r}=Q_{\text {Albedo }}+Q_{E I R}+Q_{S C}+Q_{\text {surv.htr }}
$$


where $Q_{r}=$ heat radiation from radiator to space,

$\mathrm{Q}_{\text {Albedo }}=$ Albedo flux absorbed,

$\mathrm{Q}_{\mathrm{EIR}}=$ Earth emitted IR radiation absorbed,

$\mathrm{Q}_{\mathrm{sc}}=$ heat radiation from spacecraft, particularly solar arrays, to radiator,

$\mathrm{Q}_{\text {surv-hts }}=$ survival heater power.

Presently, the cold survival temperature limit of the BAT PWBs and BCDH PWBs is $-20^{\circ} \mathrm{C}$, which is $40^{\circ} \mathrm{C}$ colder than the operating mode temperature requirement. If the conduction coupling from the DAP to the radiator is constant, in order to maintain the BAT temperature above $-20^{\circ} \mathrm{C}$, the value of $\mathrm{Q}_{\text {surv-hu }}$ in the worst cold case is very high.

\section{USE LOOP HEAT PIPES TO MEET THERMAL REQUIREMENTS}

If the conduction couplings from the DAP to the radiator can be varied, there is no need to maintain $Q_{r}$ constant in Equation (1), and therefore $Q_{o p h x}$ can be minimized in the operating mode. Also, there is no need to maintain $Q_{r}$ constant in Equation (2), and therefore $Q_{\text {sur-tur }}$ can be minimized in the safehold mode. Variable conduction couplings can be obtained by using variable conductance heat pipes (VCHPs) or LHPs.

A ROM cost estimate by a heat pipe vendor shows that the cost of a VCHP system is about the same as that of a LHP system, not including the nonrecurring engineering (NRE) cost. The advantages of LHPs are as follows. LHPs do not need to be horizontal to overcome the problem of gravity in ground testing. The heat transport capacity of LHPs is much higher. The diameter of LHP condensers is much smaller, and therefore they are more flexible, and can be made in a serpentine form easily. The number of LHPs needed is one-half that of VCHPs. Therefore, the number of reservoirs and active heater control for the reservoirs is one-half that of VCHPs, and the heater power for the reservoirs is significantly reduced. LHPs can have flexible lines so that the radiator panels can be swung open like a door to gain access to the DAP. The LHP technology is a reliable and proven technology. ${ }^{4.5,6}$

Each LHP has a compensation chamber, which is actively controlled by kapton heaters and an electronic heater controller. There are redundant heater circuits. The peak heater power is $15 \mathrm{~W}$ per compensation chamber. The temperature feedback to the heater controller is from a thermistor on the exterior of the compensation chamber. The set point of the controller is required to be adjustable in flight. The compensation chamber needs to be cold biased for active heater control. When the $\mathrm{CZT}$ detector temperature is below $20^{\circ} \mathrm{C}$, the LHPs reduce the effective conductance to the radiator. When the detector temperature is above $20^{\circ} \mathrm{C}$, the LHPs increase the effective conductance to the radiator. The effective conductance from the $\mathrm{CZT}$ detectors to the radiator is varied to maintain the LHP evaporator temperature as constant as possible. Variation of the effective conductance is accomplished by controlling the flow rate of the working fluid to modulate the heat transfer to the radiator. The heaters on the DAP act as trim heaters.

In the safehold mode, the power to the operating mode heaters is cut off. The active heater control loop is switched to the survival heater circuit. The cold survival temperature limit of the DM PWBs and BCDH PWBs is $-20^{\circ} \mathrm{C}$. The LHP compensation chamber heater controller set point needs to about $5^{\circ} \mathrm{C}$ warmer than $-20^{\circ} \mathrm{C}$ to ensure that the BAT is safe, and the survival heater power for the DM PWBs and BCDH PWBs is minimized. It must be ensured that the LHPs can be turned off.

\section{OPTIMIZATION OF LHP THERMAL SYSTEM}

To optimize the LHP thermal system for BAT, the following factors are considered:

- Working fluid for the LHPs.

- Number of LHPs, including redundancy.

- Location of the LHPs.

- Thermal interface between the LHPs and

the CCHPs embedded in the DAP.

- Cost.

Working Fluid

Presently, the power dissipation of the BAT DM PWBs and BCDH PWBs is $180 \mathrm{~W}$. In the worst cold operating case, the heater power prediction to maintain the CZT detectors at $20^{\circ} \mathrm{C}$ is approximately $27 \mathrm{~W}$. Therefore, the total waste heat to be transported by the LHPs to the radiator is about $207 \mathrm{~W}$.

A working fluid for the BAT LHPs is selected to maximize the heat transport capacity and to minimize the risk of freezing. For a given heat load, which is presently $207 \mathrm{~W}$, the heat transport capacity dictates the number of LHPs required and the maximum allowable heat transport distance. The minimum flight temperature prediction of the BAT radiator in the worst cold safehold case is $-90^{\circ} \mathrm{C}$, which is $12^{\circ} \mathrm{C}$ colder than the freezing point of ammonia. On the other hand, propylene has a freezing point of $-185^{\circ} \mathrm{C}$. The disadvantage of propylene is that its heat capacity is significantly lower than that of ammonia.

To use ammonia as the working fluid for the BAT LHPs, survival heaters and heater controllers or thermostats need to be added to the radiator and LHP lines that have no contact with the radiator. To minimize the risk of freezing, the kanton film heaters must be spread out over the entire radiator. To 
maintain the radiator at $-70^{\circ} \mathrm{C}$ in the worst cold safehold case, the survival heater power needed is 52 $\mathrm{W}$ peak or $35 \mathrm{~W}$ orbital average. The peak survival heater power for the radiator alone exceeds the survival heater power budget for BAT. Additionally, survival heater power is needed to maintain the detector modules at $-20^{\circ} \mathrm{C}$, and the LHP reservoirs at about $-15^{\circ} \mathrm{C}$. Because the survival heater budget for BAT is only $50 \mathrm{~W}$, it is not possible to use ammonia as the working fluid.

Another problem of using ammonia is related to the operating temperature range of the heater adhesive. The minimum temperature recommended by the heater manufacturers for the adhesive on the heater is $-32^{\circ} \mathrm{C}$ without aluminum backing, and $-54^{\circ} \mathrm{C}$ with aluminum backing. Even if the survival heater power budget can be increased to allow the use of ammonia, a $-70^{\circ} \mathrm{C}$ radiator temperature is significantly colder than the minimum heater adhesive temperatures recommended by the heater manufacturers. One way to prevent the heaters from debonding is to use kapton heaters with aluminum backing and maintain the radiator above $-54^{\circ} \mathrm{C}$. However, it requires an additional $50 \mathrm{~W}$ peak survival heater power, and it is of course unacceptable. An alternative is to add aluminum plates to press the heaters against the radiator with a good contact pressure. The aluminum plates need to be bolted to the radiator. While feasible, this approach adds mass. Also, the radiator is only $0.159 \mathrm{~cm}(.0625$ inch) thick, the heaters must be over the entire radiator.

\section{Number of Loop Heat Pipes}

For a given heat load and a given heat transport distance, the working fluid for the LHPs determines the number of LHPs required. To minimize the risk of a mission failure, the minimum number of LHPs is two, regardless what the working fluid is.

The BAT radiator is approximately $1.19 \mathrm{~m}$ wide and $0.9 \mathrm{~m}$ tall. If the LHP condensers are in a serpentine form across the radiator width five times, the total heat transport distance is about $5 \mathrm{~m}$. For example, if two LHPs are used, each must be able to transport a minimum of $207 \mathrm{~W}$ over a $5-\mathrm{m}$ distance. Nominally, each of the two LHPs transports $103.5 \mathrm{~W}$. But, if one of them fails, the remainder needs to transport $207 \mathrm{~W}$. A margin for the heat transport capacity is also needed. If one LHP, using propylene as the working fluid, is capable of transporting $207 \mathrm{~W}$, plus a margin, over a $5-\mathrm{m}$ distance, there is no need to consider ammonia. If propylene increases the number of LHPs by a factor of two or more, ammonia could be considered, provided the survival heater power budget for BAT can be increased and the risk of heater debonding can be minimized.

Thermal analysis by Dr. Jentung $\mathrm{Ku}^{7}$ showed that if double condensers are used, a LHP with propylene as the working fluid achieves a heat transport capacity of approximately $300 \mathrm{~W}$. Therefore, two redundant LHPs, using propylene as the working fluid, are adopted.

\section{Location of LHPs}

The compensation chambers of the LHPs need to be cold biased for active heater control. If they are outside the graded-Z shields/MLI and have a good view factor to space, they can radiate heat to space. If they are inside the graded $-Z$ shields/MLI, they may be thermally coupled to radiators outside the graded- $Z$ shields/MLI by heat pipes or heat straps. The disadvantages are extra mass and structural support for the radiators and heat pipes or heat straps. It is thermally less efficient because the interface area between the compensation chamber and heat pipe or heat strap is small, and the compensation chamber wall is stainless steel, which is not a good conductor. The second disadvantage of having the LHPs inside the graded- $Z$ shields is that cutouts on the graded- $Z$ shields/MLI are needed for penetrations of the LHP liquid lines, vapor lines, and electrical harness for the LHP heaters and heater controllers. These cutouts are potential leaks of the graded- $Z$ shields to prevent gamma rays from entering BAT from the sides. The third disadvantage of having the LHPs inside the graded- $Z$ shields is that if the LHPs are on the same side of BAT, not all the CCHPs have direct contact with the LHP evaporators, due to the room already used by the base of the struts. These are the reasons why the LHPs are located outside the graded- $Z$ shields/MLI. To accommodate the LHPs outside the graded-Z shields/MLI, the Detector Array Plate needs to be extended $8.89 \mathrm{~cm}(3.5 \mathrm{inch})$ on the $-\mathrm{Y}$ or $+\mathrm{Y}$ side, or both.

With the LHPs outside the graded-Z shields, it is easy to gain access to these components for visual inspection, leak checks, adjustments or repairs, if needed. An access door is not need.

Thermal interface between LHPs and Embedded CCHPs

A trade study on having two LHPs on one side of BAT versus one LHP on each side has been performed. To accommodate two LHPs by an $8.89 \mathrm{~cm}$ ( 3.5 inch) extension of the Detector Array Plate on the -Y side, the length of each evaporator is limited to $36.12 \mathrm{~cm}$ (14.22 inch) in the "Flat" DM design, which is the current baseline. It is shown in Figure 5. The diameter of the evaporator is $2.54 \mathrm{~cm}$ ( 1 inch). The heat flow of about $200 \mathrm{~W}$ is from the $+Y$ side of the DAP to the $-Y$ side, and then into the LHPs across the interfaces between the LHP evaporators and embedded CCHPs. There are two header CCHPs, one on each side of the LHPs. If one LHP fails, the header CCHPs and remaining LHP can transfer all the heat from the 
embedded CCHPs to the LHP evaporator. The header CCHPs have a square cross section. Its size is maximized to $1.905 \mathrm{~cm}(0.75$ inch) to maximize the thermal interface area with the LHP evaporators and embedded CCHPs. Figure 6 shows the LHPs and embedded CCHPs. A thermal analysis by Dr. Jentung $\mathrm{Ku}^{6}$ showed that with a $36.12-\mathrm{cm}$ (14.22-inch) evaporator length, there is sufficient heat transport capacity and pressure for the LHPs,

If there is an $8.89-\mathrm{cm}(3.5-\mathrm{inch})$ extension of the Detector Array Plate on each of the $+Y$ and $-Y$ sides to accommodate one LHP on each side, the length of each evaporator can be maximized to $45.72 \mathrm{~cm}$ (18 inch). Figure 7 presents the layout. The $45.72-\mathrm{cm}$ length is the maximum acceptable in the current technology. Adding one extension will add two header CCHPs. It increases the thermal interface area between the header CCHPs and embedded CCHPs, and reduces the temperature gradient between the embedded CCHPs and LHPs substantially. The temperature gradient is strongly dependent on the contact resistance at the interfaces. It directly affects the radiator sizing, and can be validated only in the BAT thermal balance test. Having one LHP on each of the $+Y$ and $-Y$ sides provides more design margins in the radiator size. It does not have any significant mechanical impact. It increases the cost by $\$ 5,000$ and increases the mass by about $1.4 \mathrm{~kg}$. Having one LHP on each side is thus preferred. To minimize the temperature gradient of the DMs, embedded CCHP \#4 and \#5, which have thermal contacts with both the LHP evaporators, will have thermal contact with only half of the LHP evaporator and one of the two header CCHPs on the $-Y$ side.

\section{Cost}

The cost of the LHPs can be reduced by reducing the number of flight units of LHPs. Note that the cost of NRE of the LHPs and Engineering Test Unit testing is independent of the number of LHPs used for flight. ROM cost estimates by two LHP vendors revealed that the cost of a LHP flight unit is small compared to the NRE cost. Reducing the number of LHP flight units from two to one reduces the total cost by about $10 \%$. Therefore, two redundant LHPs are adopted.

\section{Thermal Balance Test}

In the BAT instrument thermal balance test and SWIFT observatory thermal balance test, the embedded CCHPs need to be in a horizontal plane to overcome the problem of gravity. A tilt of up to 0.3 inch is acceptable. Having both LHPs on the $-Y$ side allows the embedded CCHPs to tilt more than 0.3 inch, with the $-Y$ side higher than the $+Y$ side, so that the CCHPs are in the reflux mode. Having one LHP on each of the $-Y$ and $+Y$ sides, if the tilt cannot be maintained within 0.3 inch, the thermal system is tested in the "one LHP failure" mode. To adjust the tilt to less than 0.3 inch, an inclinometer can be placed in the vacuum chamber.

\section{HEATER POWER REOUIREMENT}

To minimize the survival heater power to within the survival heater power budget, the $8.89-\mathrm{cm}$ extensions of the Detector Array Plate are insulated with MLI blankets. When the LHP compensation chambers reach $-15^{\circ} \mathrm{C}$ in the safehold mode, they shut off the effective conductance from the evaporators to the condensers on the radiator completely. A $15 \mathrm{~W}$ heater power is needed for each of the two compensation chambers. It is also needed for the BAT due to radiative heat leaks from the MLI blankets, and parasitic heat conduction through the LHP lines to the radiator. Heater power is required to startup the LHPs. After launch or after the safehold mode, before the BAT instrument is turned on, the startup heaters are powered on for a short time. They are located at the evaporators. The startup heater power is estimated to be $75 \mathrm{~W}$ per LHP. The startup heaters for the evaporators of the LHPs need to be commanded on or off.

\section{RADIATOR SIZING}

The radiator is made of $0.15875 \mathrm{~cm}(0.0625$ in) thick aluminum alloy. By detailed analysis, with the LHP condenser legs spaced $12.7 \mathrm{~cm}$ (5 inch) apart on the radiator, the fin efficiency is better than $96 \%$. The area of the BAT radiator is sized to satisfy the thermal requirements of the CZT detectors in the worst hot operating case first, with a $25 \%$ heater power margin. The parameters stacked in the worst hot case are EOL thermo-optical properties, winter solstice environment, and $90^{\circ}$ sun angle. After the radiator has been sized, the active heater capacity is sized to meet the thermal requirements in the worst cold operating case with a $25 \%$ heater power margin. With this heater capacity, the heater power margin in the worst hot case is much larger than $25 \%$. The GSFC design values of solar constant, albedo, and Earth emitted IR radiation are used in the thermal analysis. Table 1 presents the values. The radiator size is $1.194 \mathrm{~m} \times 0.902 \mathrm{~m}$. A $20^{\circ} \mathrm{C}$ temperature gradient from the $\mathrm{CZT}$ detector to the radiator is assumed. It includes a gradient of $6^{\circ} \mathrm{C}$ from the CZT detector to the embedded CCHPs, a gradient of $9^{\circ} \mathrm{C}$ from the embedded CCHPs through the LHPs to the radiator, and a $5^{\circ} \mathrm{C}$ margin. 
Figure 5. Two LHPs on One Side of BAT.

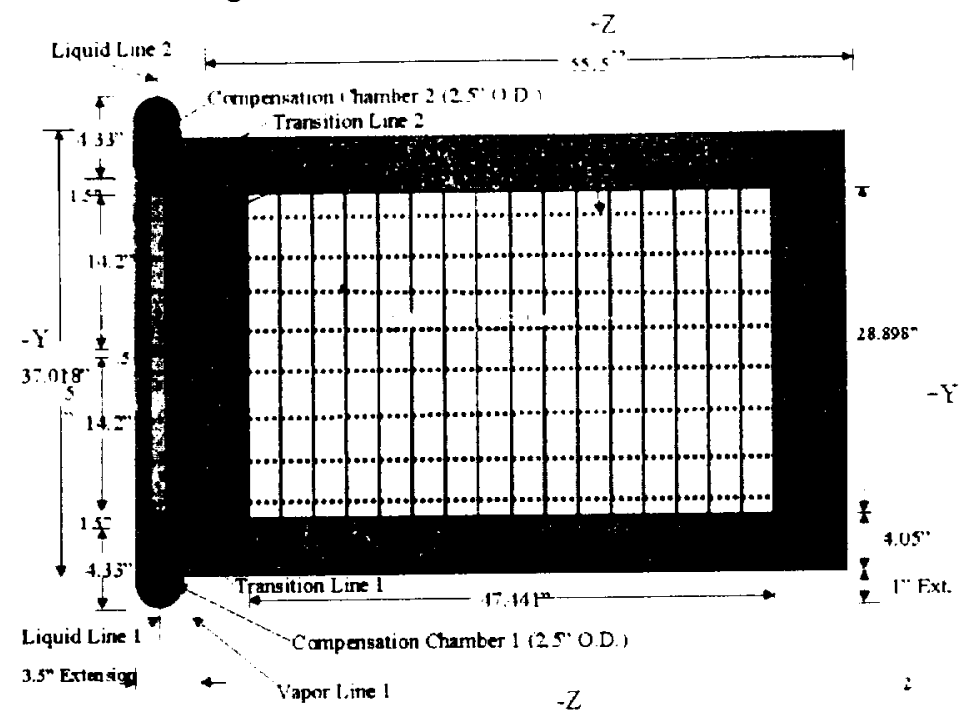

Figure 6. LHP and Embedded CCHP Configuration.

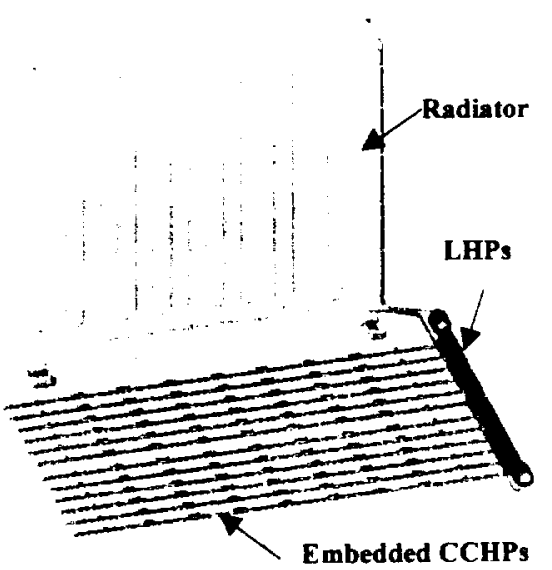

Figure 7. One LHP on Each Side of BAT.

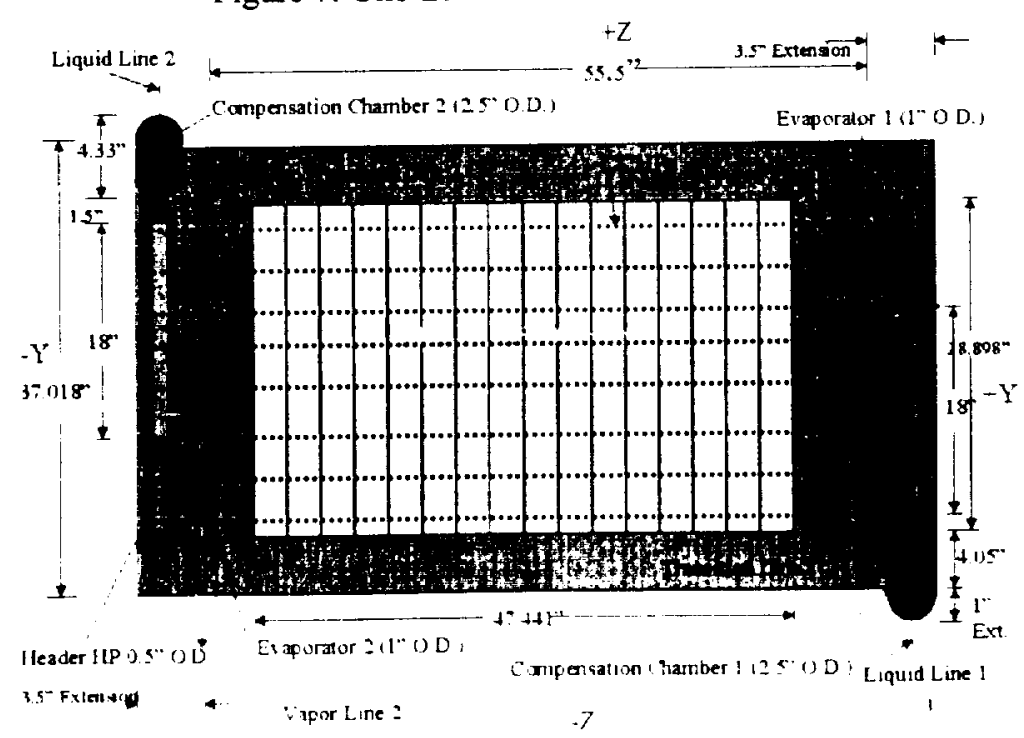


Table 1. GSFC Design Values of Environmental Constants.

\begin{tabular}{|c|c|c|}
\hline & Minimum & Maximum \\
\hline Solar Constant $\left(\mathrm{W} / \mathrm{m}^{3}\right)$ & 1287 & 1419 \\
\hline Albedo & 0.25 & 0.35 \\
\hline $\begin{array}{c}\text { Earth Emitted IR } \\
\text { Radiation }\left(\mathrm{W} / \mathrm{m}^{2}\right)\end{array}$ & 208 & 265 \\
\hline
\end{tabular}

\section{FLIGHT TEMPERATURE AND HEATER POWER PREDICTIONS}

Figure 8 presents the transient flight temperature prediction of the nominal CZT detector temperature in the worst hot case in the science mode. The thermal design meets the temperature stability requirement of $1^{\circ} \mathrm{C}$ rate of change on any time scale. Also, the $1^{\circ} \mathrm{C}$ maximum temperature gradient requirement of the 256 detectors is satisfied by the embedded CCHPs and active control heaters. The heater power needed is 45 $\mathrm{W}$ peak, including $30 \mathrm{~W}$ for the LHP compensation chambers, and the orbital average heater power is 30 W.

Figure 9 presents the transient flight temperature predictions of the nominal CZT detector temperature in the worst cold case in the science mode. The thermal design meets the temperature stability requirement of $1^{\circ} \mathrm{C}$ rate of change on any time scale. Also, the $1^{\circ} \mathrm{C}$ maximum temperature gradient requirement of the 256 detectors is satisfied by the embedded CCHPs and active control heaters. The heater power needed is $50 \mathrm{~W}$ peak, including $30 \mathrm{~W}$ for the LHP reservoirs, and the orbital average heater power is $34 \mathrm{~W}$. The heater power is higher than the worst hot case because the radiative heat leak through the BAT MLI blankets is larger. If LHPs are not used to vary the effective conductance from the DMs to the radiator, the peak heater power required in the worst cold case is $144 \mathrm{~W}$, and the orbital average is $97 \mathrm{~W}$. It exceeds the current peak heater power budget of $60 \mathrm{~W}$ significantly.

In this thermal design concept, there are two stages of active thermal control, one at the LHPs, and the other at the DMs. Therefore, the flight temperature predictions of the CZT detectors are very stable, in both the worst hot and worst cold cases.

In the safehold mode, the survival heater power needed is only $44 \mathrm{~W}$ peak, including $30 \mathrm{~W}$ for the LHP reservoirs, and $14 \mathrm{~W}$ due to radiative heat leaks through the BAT MLI blankets and the parasitic heat conduction from the embedded CCHP to LHP interface to the radiator. It is within the $50 \mathrm{~W}$ survival heater power budget. The orbital average survival heater power is $33 \mathrm{~W}$. If LHPs are not used to vary the effective conductance from the DMs to the radiator, the peak survival heater power is $186 \mathrm{~W}$, and the orbital average is $125 \mathrm{~W}$. The peak survival heater power is more than three times the budget.

Figure 8. Flight Temperature Predictions of $\mathrm{CZT}$ in Worst Hot Case.

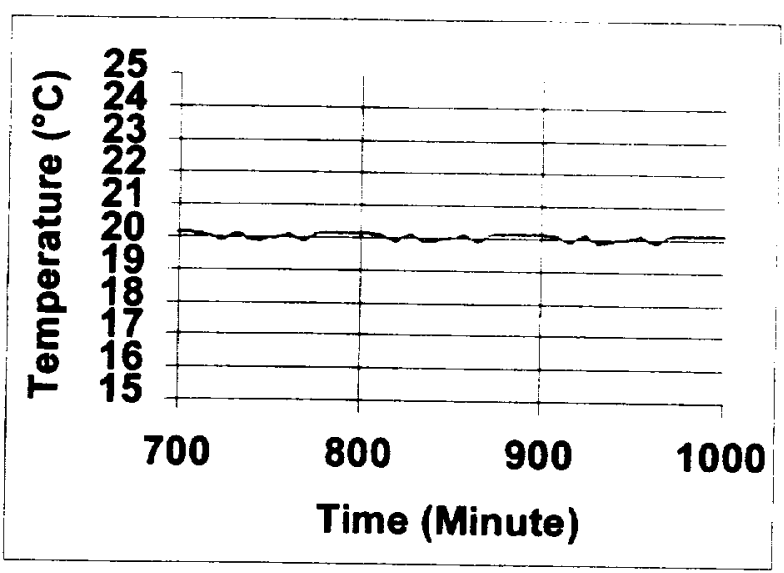

Figure 9. Flight Temperature Predictions of CZT in Worst Cold Case.

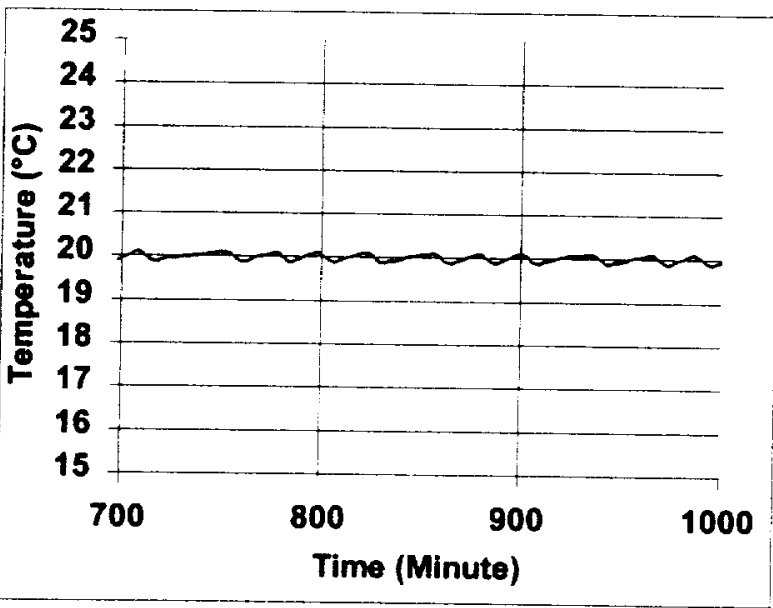

\section{SUMMARY AND CONCLUSIONS}

The maximum allowable temperature gradient of the $256 \mathrm{CZT}$ detectors is $1^{\circ} \mathrm{C}$. Also, the maximum allowable rate of temperature change of the ASICs of the $256 \mathrm{DMs}$ is $1^{\circ} \mathrm{C}$ on any time scale. The CZT detector temperature is specified as $20^{\circ} \mathrm{C}$. The total power dissipation of the DMs and BCDH is $180 \mathrm{~W}$. The results of thermal analysis show that the thermal requirements and heater power budget are satisfied by a thermal design concept that includes the following:

- The DMs are cold biased, and active heater control is used.

- Two redundant heater circuits per DM Block.

- Each heater circuit has an electronic proportional controller with a $\pm 0.25^{\circ} \mathrm{C}$ accuracy.

- Eight $1.27-\mathrm{cm}$ diameter CCHPs, using ammonia as the working fluid, are embedded in the detector array 
plate to minimize the temperature gradient of the DMs.

-Two LHPs, with propylene as the working fluid, transport the waste heat from the embedded CCHPs to the radiator.

-The LHPs are located outside the graded-Z shields/MLI.

-One LHP on the $+Y$ side and one on the $-Y$ side maximizes the thermal interface conductance, and minimizes the temperature gradient from the embedded CCHPs to the LHP evaporators.

-The diameter of the LHP evaporator is $2.54 \mathrm{~cm}$, and the evaporator length is $45.72 \mathrm{~cm}$.

-Each LHP evaporator has two redundant header CCHPs, which have a $1.905-\mathrm{cm}(0.75$-inch) outer diameter.

-The evaporator, compensation chamber, and transition line of each LHP, and the header heat pipes are mounted to the top of an $8.89-\mathrm{cm}$ extension of the detector array plate.

-Each LHP has double condensers.

- The LHP condensers are in a serpentine form on the radiator.

-Each LHP compensation chamber has two redundant heater circuits, and each heater circuit includes an electronic proportional controller.

-The radiator is a $1.194-\mathrm{m} \times 0.092-\mathrm{m}$, and $0.15875-$ $\mathrm{cm}$ thick aluminum plate.

- The radiator is located on the anti-sun side of the SWIFT spacecraft.

-The thermal coating on the radiator is AZW-LA-1I white paint or equivalent.

The heater controllers for DMs and the LHP compensation chambers have adjustable set-points in flight. Each of the LHP evaporators has a $75 \mathrm{~W}$ startup heater.

\section{REFERENCES}

1. YSI Precision Temperature Group, "Resistance Data for YSI Thermistors," YSI, Dayton, Ohio.

2. Kauder, L., Re: AZ-Tek White Paint, e-mail to $M$. Choi, Feb. 20, 2000.

3. AZ-Tek, NASA OPM Reflectometer flight data of AZW/LA-1I white paint taken in 1997.

4. $\mathrm{Ku}, \mathrm{J}$., Operating Characteristics of LHPs, SAE Technical Paper Series 1999-01-2007.

5. Kaya, T. and $\mathrm{Ku}$, J., A Parametric Study of Performance Characteristics of LHPs, SAE Technical Paper Series 1999-01-2006.

6. Kaya, T. and Ku, J., Ground Testing of LHPs for Spacecraft Thermal Control, AIAA Paper 993447.

7. Ku, J., Re: SWIFT thermal design meeting, e-mail to M. Choi, May 2, 2000. 
